\title{
An Acoustic Study of Vowel \\ Pharyngealization in Egyptian Arabic
}

\author{
Amira Aboshirif and Khaled Rifaat
}

Department of Phonetics and Linguistics, Faculty of Arts,

University of Alexandria, Alexandria, Egypt 
vry 


\section{Abstract:}

The purpose of the study is to investigate the effect of pharyngeal consonants on the Egyptian Arabic (EA, henceforth) vowels in a quantitatively adequate experimental setting. A Hundred subjects ( 35 males, 35 females, and 30 children) read the eight EA vowels: five long /a:, i:, u:, e:, o:/and three short $/ \mathbf{a}, \mathbf{i}, \mathbf{u} /$, in three contexts. The first context is a plain $/ \mathrm{hVd} /$. The second and third contexts are pharyngealized $/ \partial \mathrm{Vd} /$ and $/ \square \mathrm{Vd} /$. The three contexts compose stressed syllables of twenty four sense words. The fundamental frequency $(\mathrm{F} 0$ ) and the first two formants are measured. Acoustic measurements are obtained by using PRAAT software. The results illustrate that pharyngealized acoustic vowel space is larger than plain one. This enlargement is mainly due the two short vowels $/ \mathbf{a}, \mathbf{u} /$. The most affected sound by pharyngealization is the short vowel $/ \mathbf{a} /$.

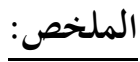

تهدف هذه الدراسة إلى اختبار تأثير الأصوات الحلقية على صوائت العربية المصرية فى ظروف تجريبية

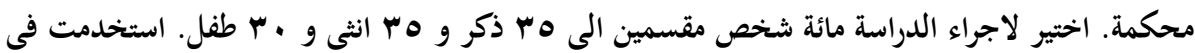

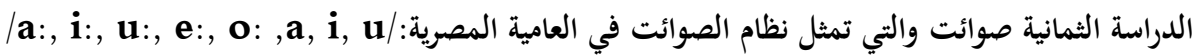

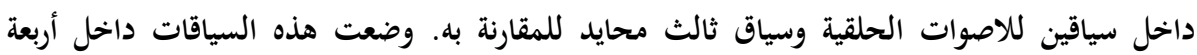

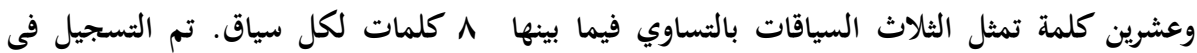
استوديو قسم الصوتيات واللسانيات بكلية الآداب جامعة الأسكندرية ـ وقد قيس المكونين الصوتيين الأول والثاني بالإضافة إلى التردد الأساسي وذلك باستخدام برنامج برات PRAAT.

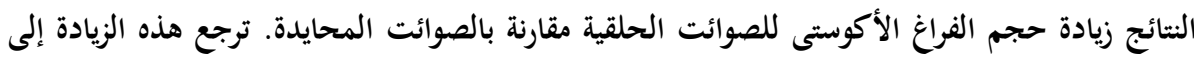
الصائيين /a, u/ ـ وقد ظهر الصائت /a / كأكثر الأصوات المتأثرة بظاهرة التحليق. 


\section{Introduction:}

Pharyngeal consonants are specific speech sounds which are rarely used among the languages of the world. Such sounds considered to be unusual speech sounds, because the great majority of consonant strictures are produced in the oral cavity not in the pharyngeal one (Delattre, 1971).In pharyngeal articulation the tongue root retracts towards the back wall of the pharynx in order to reduce the size of pharyngeal cavity. Pharyngealization is a secondary articulation of consonants or vowels by which the pharynx or the epiglottis is constricted during the articulation of the sound. The presence of pharyngeals and pharyngealized sounds is considered as a specific phenomenon in Arabic.

The term pharyngealization has been used to describe different classes of sounds. Some scholars restrict the term to the two sounds $\mid \square, \partial /$ Ghowail (1987); Wahba (1988) and Elgendy (2001). Whereas others add to these two sounds the uvulas /x, P,q/ (Delattre, 1971); Another group of scholars add also the emphatic four sounds $/ \mathrm{s} \Rightarrow, \mathrm{z} \Rightarrow \Rightarrow \Rightarrow \Rightarrow, \mathrm{t} \Rightarrow, \mathrm{d} \Rightarrow /($ Boxberger, 1981 ), and (Norlin, 1985). The source of this terminology problem is that all these classes are characterized by a constriction in the pharynx.

El_Dalee (1984) tries to solve the misleading 
terminology by using the term retraction to emphatic and emphasized sounds and restricts the term pharyngeal to the two sounds $\mid \square, \partial /$.

To my knowledge, there is not any study that dealt with Egyptian Arabic pharyngealized vowels as a major aim. Most of the studies investigated pharyngeal consonants as specific targets, and provided one or more vowel acoustic measurements only as a tool to test originally different hypotheses Delattre (1971); Norlin (1983); Ghowail (1987), and Elgendy(2001). Others study pharyngealized vowels within a general descriptive acoustic profile of consonants and/or vowels ,Elgendy( 1982); AL- Ani (1970), and Wahba (1988)

Acoustic investigation of EA pharyngealized vowels have gained less concern in previous studies, as such studies focused mainly on consonants and deal with vowels as being complementary area of the study rather than a main objective.. One of the few studies that has been devoted to EA vowels has been introduced by Wahba (1988), who studies all EA eight vowels.

The aim of the present study is to investigate the effect of the two pharyngeal consonants $|\square, \partial|$ on the Egyptian Arabic vowels in a more quantitatively adequate experimental setting.

Indeed, the present study uses much data and it vrq 
has a wider scope than previous ones, and as such it would hopefully add more reliable description of the phenomenon.

Methodology

Speakers:

A hundred subjects participated in the study $35 \mathrm{men}$, 35women, and 30children). Men and women aged from 17 to 40 (most of them are college students from faculty of Arts, Alexandria university), while children aged from 8 to12. The majority of speakers are raised in Alexandria. Subjects with voice, language, speech disorders, and respiratory infections are excluded. Screening procedure was used to select the subjects from a large group (one hundred sixty speakers). This is basically to make sure that all participants are native Egyptians and have been born to Egyptian parents and live in Egypt.

Speech sample:

The speech sample consists of two word lists. The first list contains of 8 words including the EA eight plain vowels used in the $/ \mathrm{hVd} /$ stressed syllable context. The second list contains of 16 words includes the eight vowels in pharyngealized stressed environment $\mid \square \mathbf{V d}(\mathbf{t}) /$ and $/ \partial \mathbf{V d}(\mathbf{t}) /$ syllables, eight for each context. The researcher chose the dental stop consonants $/ \mathrm{d}, t /$ as it has no effect on steady 
state, and because of the effect of the place of articulation of the initial consonant is stronger than the final consonant (Hillenbrand, 2001) the pharyngeal consonants were used in initial position. The three contexts are included in twenty four sense words. The words were written on white cards with their representative colored pictures to facilitate reading to the children.

Recording and analysis:

The speech material was recorded in a soundproof room located at the department of Phonetics and Linguistics, Faculty of Arts, University of Alexandria, using computerized speech lab CSL model 4300 software. Such a procedure was done with males and females while speech sample of children was recorded in quite rooms either in their school or houses. The first two formants are measured in addition to F0. Formant measurements were taken at the midpoint of the vowel using wide band spectrogram with sampling rate equals $22050 \mathrm{~Hz}$. Acoustic measurements were obtained by using PRAAT software. Acoustic vowel space areas were illustrated by the first two formant frequencies ( $F 1$ and $F 2$ ), which used to characterize the size and shape of the cavities created by jaw opening $(\mathrm{F} 1)$ and tongue position (F2). Acoustic features which reflect the effect of pharyngeal sounds are increase in $F 1$ and decrease in F2. 
T-test was run on $F 1$ and F2 for plain and pharyngealized vowels in order to find out the significance of difference between the values of the four groups: male and female adults, and male and female children. The total of acoustic measurements is nine thousand six hundred, i.e., twenty four allophones multiplied by four measurements for each vowel multiplied by hundred speakers.

Results and Discussion:

a- Voiceless Pharyngeal $/ \square /$

F1 results:

In figure 3 and as reported in the literature, F1 measurements for adult males (a) showed tendency for all pharyngealized vowels after voiceless $/ \square /$ to have a higher frequency than plain counterparts. Such an increment occurs only with short vowels $/ a, i, u /$, where the $p$ value equals 0.001 . Among the three short vowels, the $/ a /$ is the most affected one $/ \square /$ followed by /u/ followed by $/ \mathbf{i} /$ ( i.e back short vowels then front short one); F1 mean for pharyngealized $/ a /$ increased by $27 \%$ of the total value of plain counterpart , $20 \%$ for short $/ \mathbf{u} /$ and $17 \%$ for short $/ \mathbf{i} /$. This significant change occurs in adult males, and with more increment for adult females, where F1 of pharyngealized $/ \mathbf{a} /, / \mathbf{u} /$, and $/ \mathbf{i} /$ is increased by $33 \%, 33 \%$, and $17 \%$ sequentially. To ${ }_{V \leqslant r}$ conclude, Among the eight 
EA vowels, only the three short vowels $/ a, i, u /$ which $F 1$ is affected by voiceless pharyngeal consonant $/ \square /$, the vowel $/ a /$ is the most affected one , F1 for /a/ increased by nearly one third in both males and females. The vowel /a/ is characterized by such an effect because /a/ has the lowest stricture of all vowels; in other words, it "has the smallest pharyngeal cavity of all vowels" (Delattre, 1971).The F1 increment in females is larger than that in the adults; this can be explained as formant frequencies vary inversely with vocal tract size. Therefore, formant frequencies are lower in men, intermediate in women, and highest in children (Koeing, 2004).
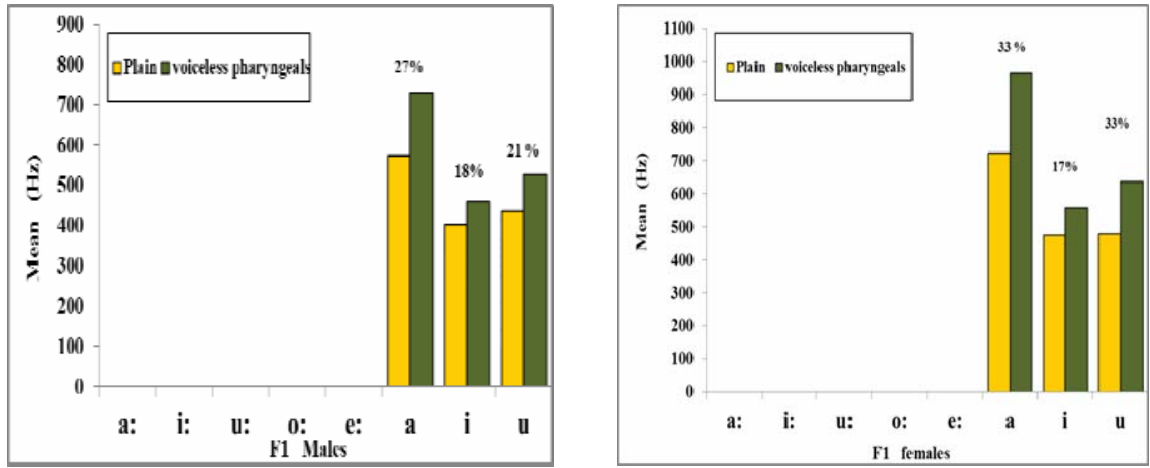

Figure 1: (a) plain verses voiceless pharyngealized vowels F1 for male speakers . (b) plain verses voiceless pharyngealized vowels F1 for female speakers

In children 'speech (figure 2), F1 shows a significant increase in only two short vowels $/ \mathbf{a}, \mathbf{u} /$. In male children /a/ F1 increased by $24 \%$, and $/ u /$ by $20 \%$, while in female 
children $/ \mathrm{a} / \mathrm{F} 1$ increased by $36 \%$, and $/ \mathrm{u} /$ by $28 \%$. F1 increment in female children is greater than in male children;/a/ increased by third or more in females while in males increased by quarter. Females in both adults and children have the greatest increase in F1.

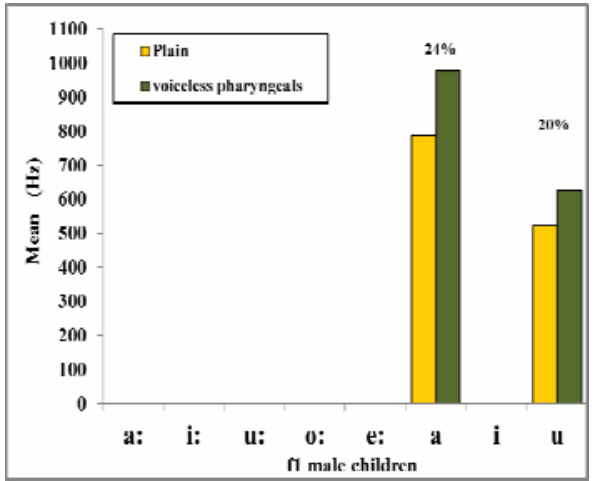

(a)

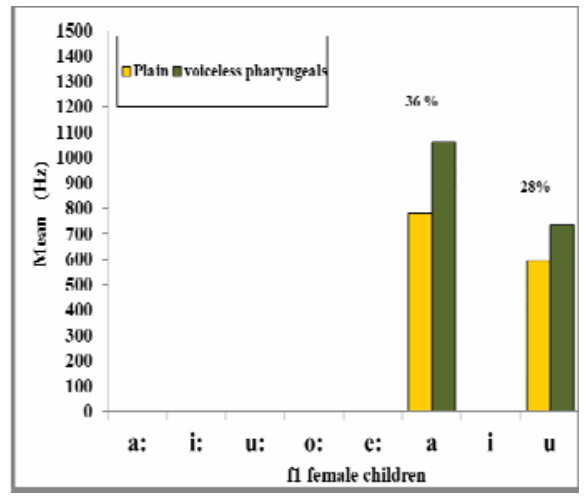

(b)

Figure 2: plain verses voiceless pharyngealized vowels F1 for male children (a) speakers and female children speakers (b)

F2 results:

F2 for voiceless pharyngealized vowels showed significant decrease in only two short vowels $/ \mathbf{a} /$ and $/ \mathbf{u} /$, where $\mathbf{p}$ value is 0.001 in both adult males and females. In males, /a/ has the greatest decrease where its F2 decreased by $14 \%$ of the total value of plain counterpart, whereas short $/ \mathbf{u} /$ decreased by $11 \%$ as shown in figure 3 (a). About $80 \%$ of male speakers participate by this change in /a/ vowel .In females, the matter is different; /u/ decreased by $13 \%$ and $/ a /$ decreased by $12 \%$ as shown in figure 3 (b); this means that changes in $\mathrm{f} \mathrm{V}_{\varepsilon}$ is not consistent between 
males and females. Additionally, the short vowel /a/ produced by males is more affected by laryngeal consonant $/ \square /$ than that which is produced by females.
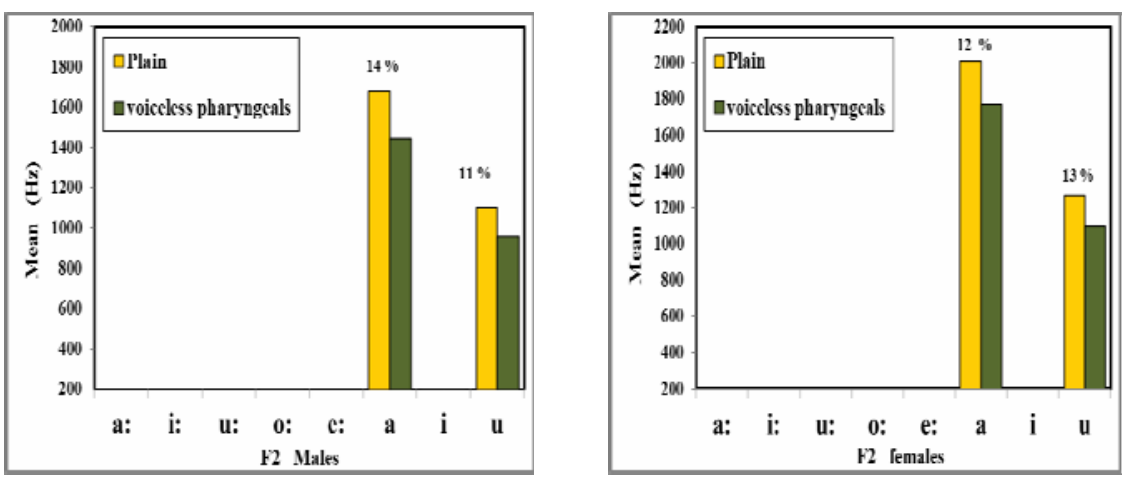

Figure 3: plain verses voiceless pharyngealized vowels F2 for male speakers(a) and (b) female speakers (b)

In male children the significance is weak in $/ \mathbf{u} /$ than in /a/.In female children, the significance is very strong; $p$ value equals 0.001 for $/ a / ; / a /$ is the only vowel which $F 2$ is affected by pharyngeal consonant. (see figure 4)

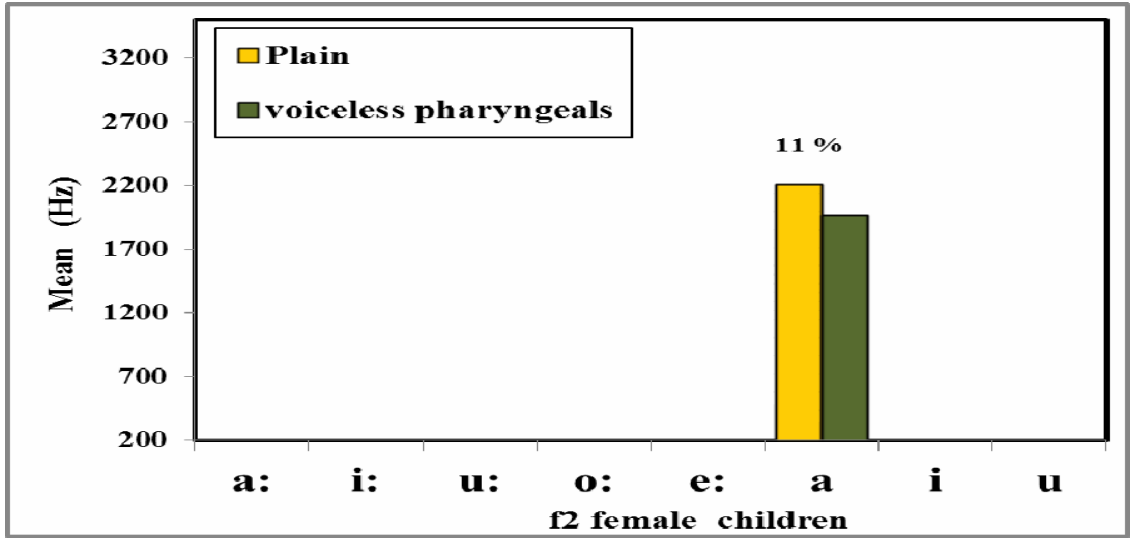

Figure 4: plain verses voiceless pharyngealized vowels F1 for female speakers 
Comparing between F1 and F2 measurements and to what extent they are influenced by the adjacent voiceless pharyngeal consonant $/ \square /$, Pharyngealized acoustic vowel space seems to be larger than plain vowel space, because of the F1 large values of the two short [ $a \Re$ ] and [ $u \Re$ ] which play an important role in enlarging the vowel space area.

In details, for adults, F1 is more affected than F2, where F1 changes in three short vowels while F2 changes in only two [aR], [uR]. In addition, the percentage of formant change in F1 is more than that of F2. For children, F1 also changes in two short vowels while F2 changes in one short vowel in females and is not affected in males at all. It could be argued then that long vowels are never affected by voiceless pharyngeal consonant $/ \square /$. Figure 5,6 shows a scatter plot for F1 F2 for plain vs voiceless pharyngealized vowels. With respect to gender; females are always affected by pharyngealized voiceless $/ \square /$ than males; this is due to the increased percentage of F1females than that of
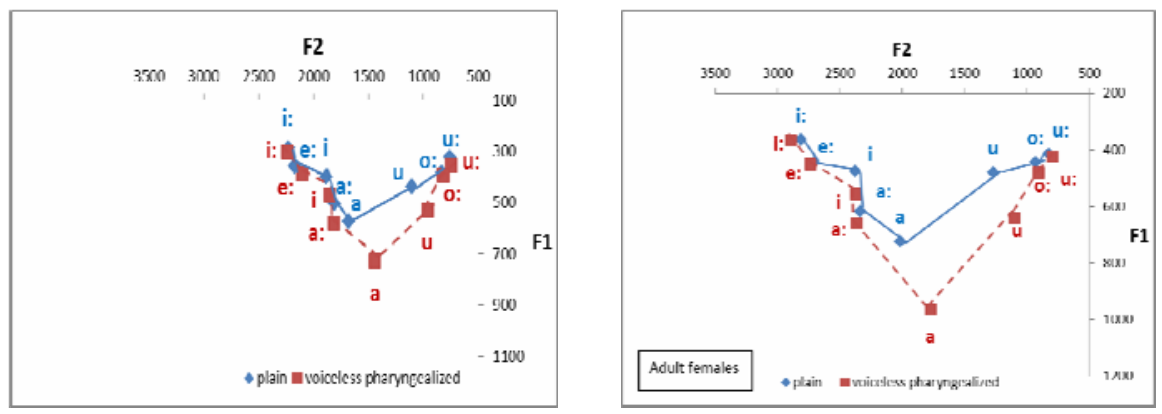

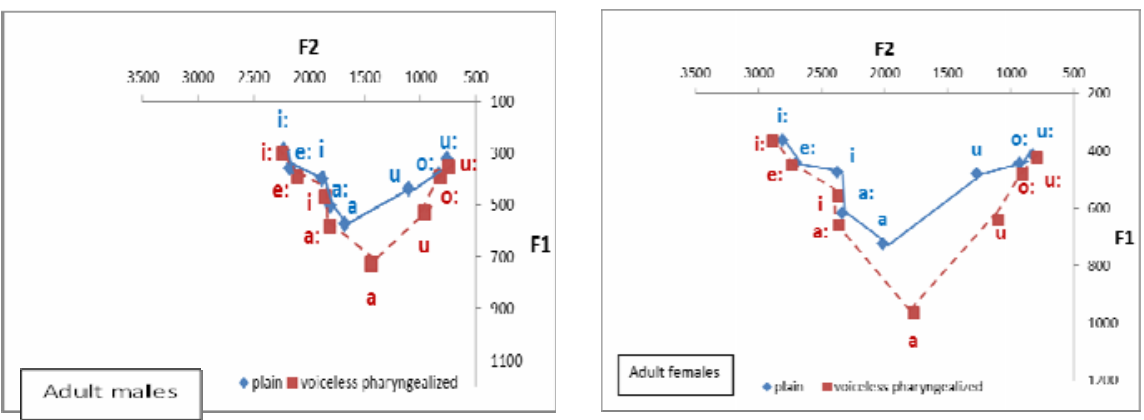

Figure5: F1plotted against F2 of plain and pharyngealized vowels for adult males and females
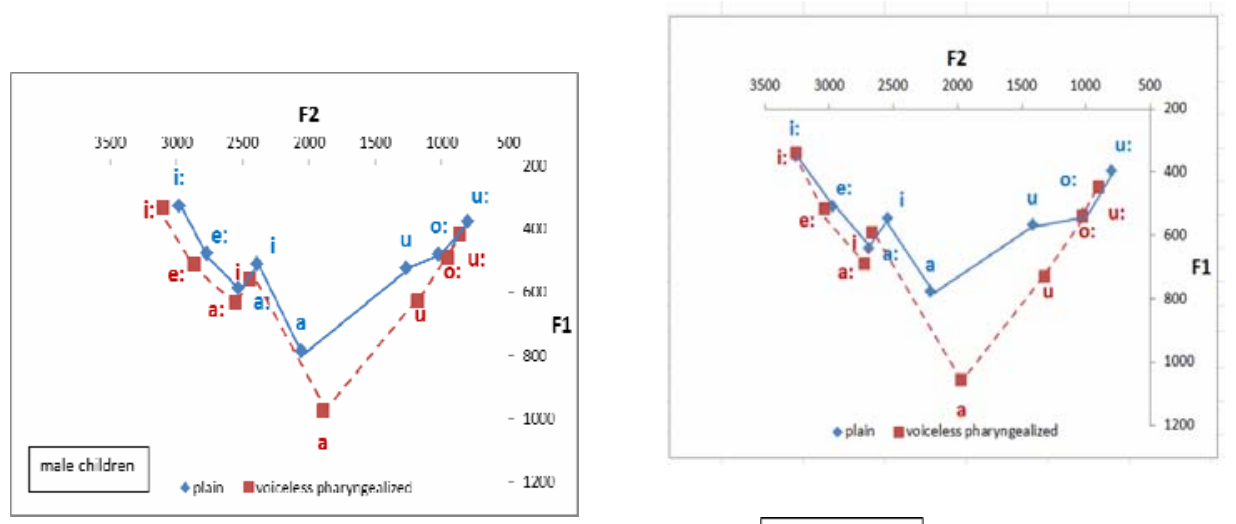

Female children

Figure 6: F1plotted against F2 of plain and pharyngealized vowels for male and female children 
b-Voiced pharyngeal $/ \partial /$ :

F1 results:

Male F1values for voiced pharyngealized vowels are clearly different from their voiceless counterparts, where it has an effect on almost all vowels except the long vowel /i: /(however this effect is minor), see figure 7 (a). Similar to F1 results of voiceless pharyngealized vowels, the greatest affected vowel is also the short vowel /a/ followed by short $/ \mathbf{u} /$ then $/ \mathbf{i} /$. In both males and females, /a/ F1 increased by nearly one third, and nearly $90 \%$ or more of speakers who increase F1.
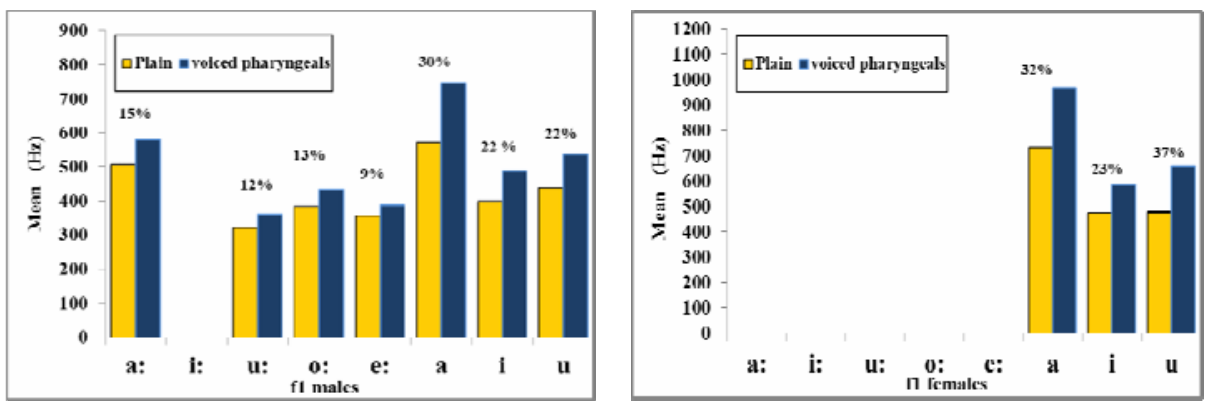

Figure 7: plain verses voiced pharyngealized vowels F1 for male speakers $(a)$ and $(b)$ female speakers $(b)$

In male and female children, only the three short vowels which affected by voiced pharyngeal $/ \partial /$, with the most significance in $/ a /$ in females where $F 1$ of $/ a /$ increased by $40 \%$ than plain counterpart where $100 \%$ of females who make this change (see figure 7 ) 


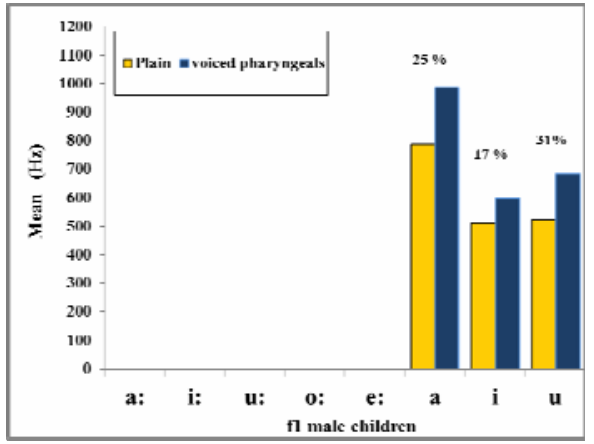

(b)

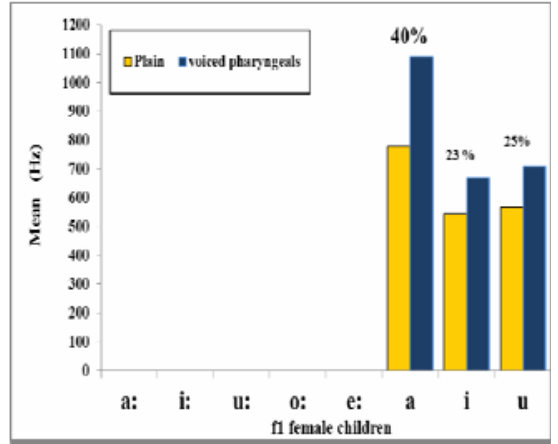

(b)

Figure 8: plain verses voiced pharyngealized vowels F1 for male children speakers (a) and (b) female children speakers.

F2 results:

F2 voiced pharyngealized vowels are lowered in males in short vowel $/ a /$, the percentage of lowering is not large equals $16 \%$ produced by $80 \%$ of all male speakers (see figure 7 (a)). In females, the F2 lowering occurred in short vowels $/ \mathbf{a} /$ and $/ \mathbf{u} /$, with $14 \%$ for $/ \mathbf{a} /$ and $13 \%$ for $/ \mathbf{u} /$ produced by little percentage of speakers(see figure $8(b))$.

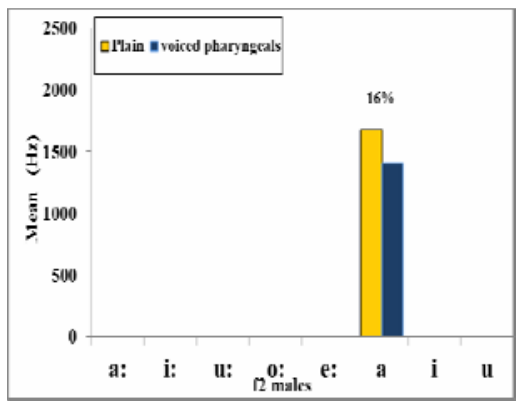

(a)

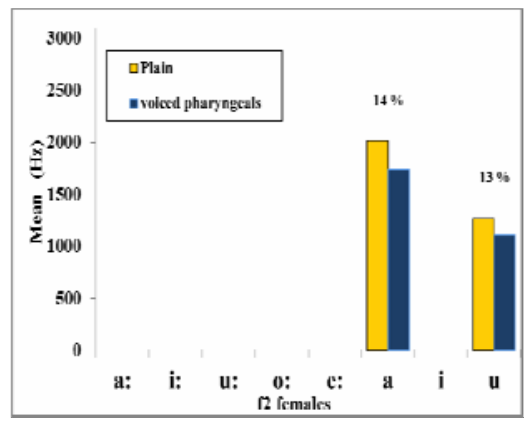

(b)

Figure 9: plain verses voiced pharyngealized vowels F2 for male speakers (a) and (b) female speakers. 
In children, the effect of voiced pharyngeal $/ \partial /$ is very weak where it changes only /a/ vowel. F2 female children is more affected than F2 of males.(See figure10)

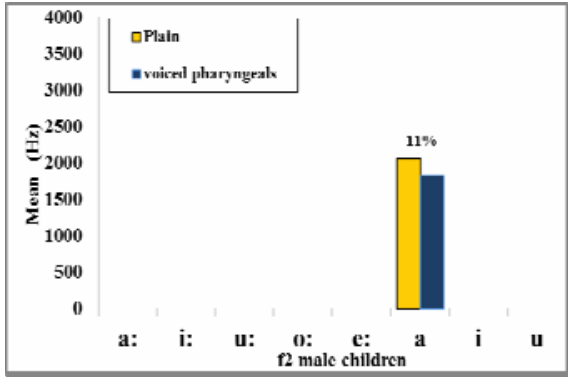

(a)

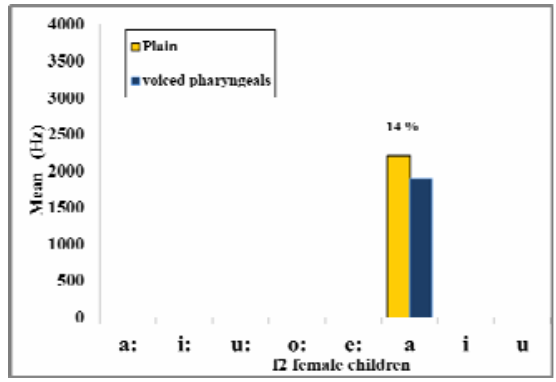

(b)

Figure 10: plain verses voiced pharyngealized vowels $F 1$ for male children speakers (a) and (b) female children speakers For F0, there is no significant difference between plain vowels and their voiced/voiceless pharyngealized counterparts in both adults and children.

Comparing F1 with F2 measurements, F1 is more affected than $F 2$ in both adult and children, Females are always affected by $/ \partial /$ than males. see figures 11,12
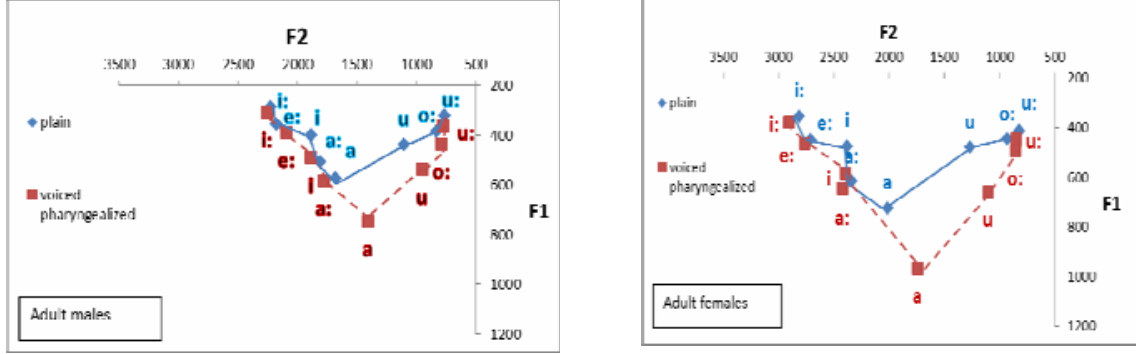

Figure 11: F1plotted against F2 of plain and voiced pharyngealized vowels for adult males and females 

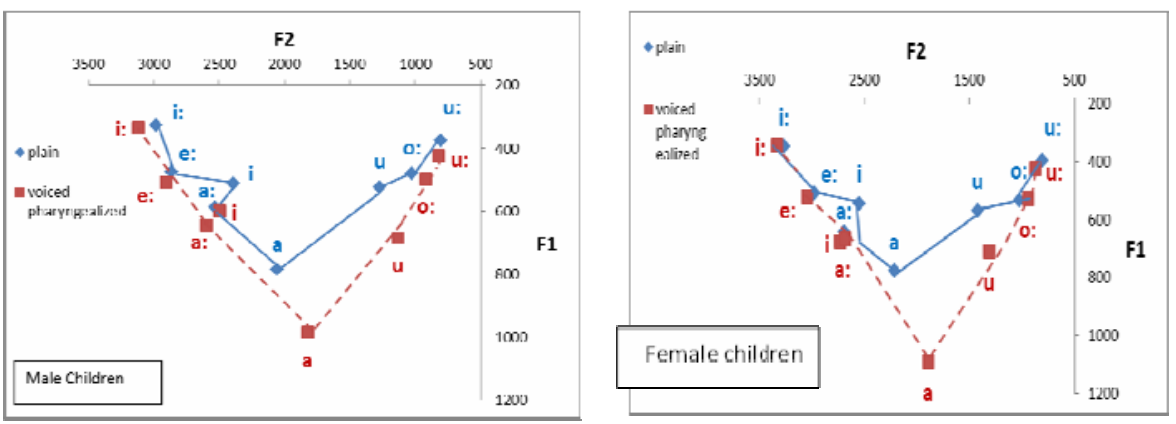

Figure 12: F1plotted against F2 of plain and voiced pharyngealized vowels for male and female children

The clear difference between $/ \square /$ and $/ \partial /$, is that $/ \partial /$ has a greater effect on $\mathrm{F} 1$ than $/ \square /$, especially in female children. This result does not agree anymore with Delattre (1971) who states that pharyngeal stricture of $/ \square /$ is narrower than for $/ \partial /$; the findings of his study seem to be different, may be because he used different ways of investigation, qualitative not quantitative ones; he uses only five speakers using $\mathrm{X}$ rays. On the contrary, $/ \partial /$ has a lesser effect on $F 2$ than $/ \square /$.

As illustrated in the scatter plot figures, the plain acoustic vowel space looks like a semi-triangle, its base is at the top, and the vertices of this base are the long vowels $i$ : and $u$ :,and its apex is at the bottom represented by the short vowel $/ \mathbf{a} /$.When vowels are pharyngealized, the triangle moves clearly away downwards (F1 increase), and slightly to the $\operatorname{right}_{(} \mathrm{F} 2$ decrease). This means that in pharyngeal context, the distance between F1 and F2 of the short vowels is smaller than those in long ones (Ghowail, 1987\& Wahba, 
1988).

To conclude, pharyngealized acoustic vowel space seems to be larger than plain vowel space; this enlargement is mainly due to large values of the two short vowels $/ \mathbf{a}, \mathbf{u} /$.The most affected sound with pharyngealization is the short vowel $/ a /$; this phenomenon can be explained in the light of Ghowail study (1987); as she observed that the low vowel /a/ is the only vowel which often appears in words including pharyngeal sounds. In addition Al-Ani (1970) refers to vowel $/ a /$ as low central vowel which is easily affected by any advancement or retraction. Also, the $/ a /$ stricture is the nearest one to pharyngeal cavity.

The earlier studies of pharyngeals fall into two categories; the first category considers pharyngeals as fricatives and the second as approximates. Catford (1977) considers both of them as approximants.

In the present study, it has been noticed that the voiced pharyngeal $/ \partial /$ is always presented by clear three formant frequencies very similar to those of vowels these pharyngeal formants are also merged greatly and smoothly with adjacent vowel formants in homogeneous way. This result does not agree with Al-Ani (1970) who studied acoustic characteristics of pharyngeals within other sounds; his study concludes that pharyngeal $/ \partial /$ is realized as 
pharyngeal stop in some of his analyzed data; his observation does not accord anymore with the present study where voiced pharyngeal $/ \partial /$ is never represented by gap or friction ;it is represented in all 1600 tokens which have been analyzed by formants knowing that the present study using $h \mathrm{Vd}$ context $i$.e pharyngeal $/ \partial /$ is used only in initial position). The results of the present study accord with Norlin study (1983), and El Gendy (2001) where they consider $/ \partial /$ as an approximant.

Concerning voiceless pharyngeal $/ \square /$, the present study describes it as a fricative pharyngeal where it is always represented in all 1600 tokens by noise friction started at nearly $1000 \mathrm{~Hz}$ and extended to $5000 \mathrm{~Hz}$. This result accord with Delattre (1971), and also with Norlin's study (1983) where he considers $/ \square /$ as pharyngealized fricative characterized by lower center of gravity and greater dispersion.

\section{Conclusions:}

Among all EA vowels, the most affected ones by pharyngeal consonants $/ \partial /, \mid \square /$ are short vowels; [a],[u], [i] sequentially. 
The short vowel $[a \Re]^{1}$ is the most pharyngealized vowel in EA, and therefore characterized by the highest $F 1$ which is compatible with pharyngeal production. The short vowel $/ \mathrm{a} /$ is pharyngealized by all selected groups adult males and females, as well as male and female children.

The sound/ $/$ / has stronger effect than $/ \square /$ where its F1 effect can expand on almost all vowels except the long vowel $\mid \mathbf{i}: /$, ,however its effect is minor on long vowels.)

The overlap between plain and pharyngealized vowels with respect to F1 frequency was much greater than that for F2 in both voiced and voiceless pharyngeal consonants $/ \square, \partial /$.i.e $F 1$ is the main reason of enlarging the acoustic vowel space of pharyngealized vowels.

${ }^{1}$ Pharyngealization can be indicated by using the symbol [ $\left.{ }^{\mathrm{C}}\right]$, the voiced pharyngeal approximant written after the pharyngealized phoneme, as in $\left[a^{\mathfrak{c}}\right]$ (the pharyngęalized equivalent of $[\mathrm{a}]$ ). 
References:

Al-Ani, S.H. Arabic phonology: an acoustical and physiological investigation. Paris: The Hague. (1970).

Boxberger, L. Acoustic characteristcs of pharyngeal and haryngealized consonants. Working papers in Linguistics and Phonetics, 6, Lund University.(1981), pp. 127- 128.

Catford, J. Fundamental problems in phonetics.

Edinburgh University Press, Edinburgh. (1977).

Delattre, $P$. Pharyngeal feature in the consonants of Arabic, German, French and America English.Phonetica , 23, (1971). pp. 129-155

Elgendy,, A. M. Aspects of Pharyngeal Coarticulation. Ph.D. thesis, Amsterdam Center for Language and Communication (ACLC). University of Amsterdam. (2001).

Ghowail, T. I. The Acoustic Phonetic Study of The Two Pharyngeals $\mid \square, \partial /$ and The Two Laryngeals $/$ ?, h/ In Arabic. Ph.D. thesis, Indiana University(1987).

Koenig,L.Towards a physical definition of vowel systems of languages. VictorH and Wasik(eds.) Hard-science linguistics. .(2004).

Norlin, K. Acoustic analysis of fricatives in Cairo Arabic. Working papers in Linguistics and Phonetics, 25, Lund University, pp. 117-118.

Wahba, K.M. Acoustic Analysis of Egyptian Colloquial Arabic Vowels: An Experimental Study. M.A.thesis, Alexandria University. (1988). 
VoY 